\title{
Cardiovascular responses of physically active colligate subjects during normal and warm conditions, and determination of sweat rates
}

\author{
Bilal DEMIRHAN ${ }^{1}$, Asim CENGIZ², Bade TEKBAS ${ }^{1}$
}

${ }^{1}$ Faculty of Sports Sciences, Ondokuz Mayıs University, Samsun, Turkey.

${ }^{2}$ Department of Physical Education and Sports, Gazi University, Ankara, Turkey.

Address correspondence to Asim Cengiz, awesome77@gmail.com

\begin{abstract}
The aim of this study was to determine the effects of elevated climate temperature on the exercise-induced physiological responses and fluid need in physically active subjects. Ten physically active colligate subjects (age: $22.79 \pm 4.98$ yrs) participated in a counter balanced cross over design that consisted of performing a cycling run (65\% VO2 max) for $30 \mathrm{~min}$ under normal and condition of wearing multiple layers of clothes, separated by 7 days. Measures of heart rate, body temperature, and rating of perceived exertion (RPE) were obtained at 10-min intervals $(0,10,20$, and $30 \mathrm{~min})$ from the onset of exercise. Sweat rates, and amount of fluid needed to replace water loss during exercise were calculated. Heart rate, body temperature, and RPE increased all the way to the end of the exercise for both conditions but more in warm conditions. These findings point out that sports facilitators should take the athletes' physiological responses in training in warm dry weather seriously, guide athletes to rehydrate with adequate amount of water.
\end{abstract}

Keywords: Running, heat, and sweat rate.

\section{INTRODUCTION}

One of the most important factors that affect exercise habits and efficiency is the environment. Conditions such as warm weather, altitude, humidity, pollution, and climate have a considerable effect on athletic performances in almost all sports. Also, heat, humidity, and weather in general were the main problems in many international sports organizations $(7,8,24)$. Since warm, humid weather even without physical effort has an impact on individuals to regulate body temperature; exercise and/or participation in any lengthened athletic experience will put in a substantial burden to the heat regulation mechanism. This issue in itself is likely to be a critical limiting factor for either bodily work or an athletic accomplishment. In addition, possibly of serious heat illness can occur (8) that can simply stop the work or performance. It is vital for the athletes to maintain core body temperature to permit for its regular genetic and mechanical functions. One of the most important things to maintain boy temperature is to sweat (4). Sweating during physical activity can rapidly result in dehydration, predominantly in profuse sweaters in warm environments. It should be distinguished that the main limiting feature for thermal homeostasis in exercising individuals is the availability of adequate drinking of water to balance for sweat fluid losses.

Exercise-induced hyperthermia may have a negative effect an athletic performance (19). It is important to consider practicable solutions to relieve nature's effect on the athletes' performance during exercise. This matter has not been adequately examined. Therefore, the purpose of this study was to compare physiological parameters of collegiate athletes for normal and warm conditions (wearing multiple layers of uniforms) during 30 minutes of cycling exercise. Also, it was indented to determine the sweat rates and fluid needs for each subject for both trials. It was expected that the subjects would be negatively affected during heat trials and fluid need would be increased. The outcome of such research should help provide safety measures and preventive measure in accordance with the athletes' hydration requirements. 


\section{MATERIAL \& METHODS}

\section{Procedures}

Ten physically active colligate subjects (age: 22.79 \pm 4.98 yrs $)$ participated in a cycling run $(65 \% \mathrm{VO} 2$ max) for $30 \mathrm{~min}$ under normal and condition of wearing multiple layers of clothes, separated by 7 days. Measures of heart rate, body temperature, and rating of perceived exertion (RPE) were obtained at 10 -min intervals $(0,10,20$, and $30 \mathrm{~min})$ from the onset of exercise. Sweat rates, and amount of fluid needed to replace water loss during exercise were calculated. The room was equipped with a cycle ergometers. Relative humidity was $(14 \pm 2)$ and $(24 \pm 9)$ in normal and warm conditions, respectively.

The subjects were introduced to the goals, design, and related risks of the research. The subjects completed approved consent form and an exercise readiness questioner. A 30-minute cycling protocol was conducted with intensity of $65 \%$ of the $\mathrm{VO} 2$ max.

The subjects were paired to complete either a 30min normal condition cycling or a 30-min warm condition. Body temperature was measured verbally. Rating of perceived exertion (RPE) and heart rate, and body temperature were determined at $10-\mathrm{min}$ intervals (13) for $30 \mathrm{~min}$ using the Borg scale and a sphygmomanometer, respectively. Heart rate was recorded using chest-strapped heart rate telemetry (Polar; Port Washington, NY).

Sweat rates were calculated with the formula as below (1). Borg scale was used to measure RPE.

Sweat Rate $(\mathrm{L} / \mathrm{hr})=\left[\right.$ Weightpre $(\mathrm{kg})-$ Weight $_{\text {post }}$ $(\mathrm{kg})]$ / Exercise duration (hr)

\section{Statistical Analyses}

Body temperature, rating of perceived exertion (RPE), and heart rate (HR) were measured during exercise in warm and normal conditions. Paired T-test was conducted for all study variables with "Excel program". The significance level was set at $\mathrm{P}<0.05$.

\section{RESULTS}

The difference in body temperature $(\mathrm{p}=0.009)$, and RPE $(p=0.024)$, sweat rate $(\mathrm{p}=0.006)$, and fluid need for every 15 minutes $(p=0.001)$ between the two conditions was significantly higher when exercising during the warm condition (Table 1, 2 and 3.) while the subjects' heart rate $(p=0.068)$ was higher in the warm condition but not significant.

Table 1. Average body temperature, heart rate, and RPE values for normal and heat trials for every ten minutes.

\begin{tabular}{|c|c|c|c|c|c|c|}
\hline \multirow{2}{*}{ Time (min) } & \multicolumn{2}{|c|}{ Heart Rate (bpm) } & \multicolumn{2}{|c|}{ Body Temperature $(\mathrm{F})$} & \multicolumn{2}{|c|}{ RPE } \\
\hline & Control & Heat & Control & Heat & Control & Heat \\
\hline 0 & 73.13 & 72.50 & 97.64 & 98.12 & 8 & 8 \\
\hline 10 & 125.38 & 142.90 & 98.56 & 99.56 & 10.8 & 11.6 \\
\hline 20 & 130.88 & 152.20 & 99.56 & 100.19 & 12.0 & 12.9 \\
\hline 30 & 134.75 & 159.20 & 99.79 & 100.77 & 12.9 & 13.9 \\
\hline
\end{tabular}

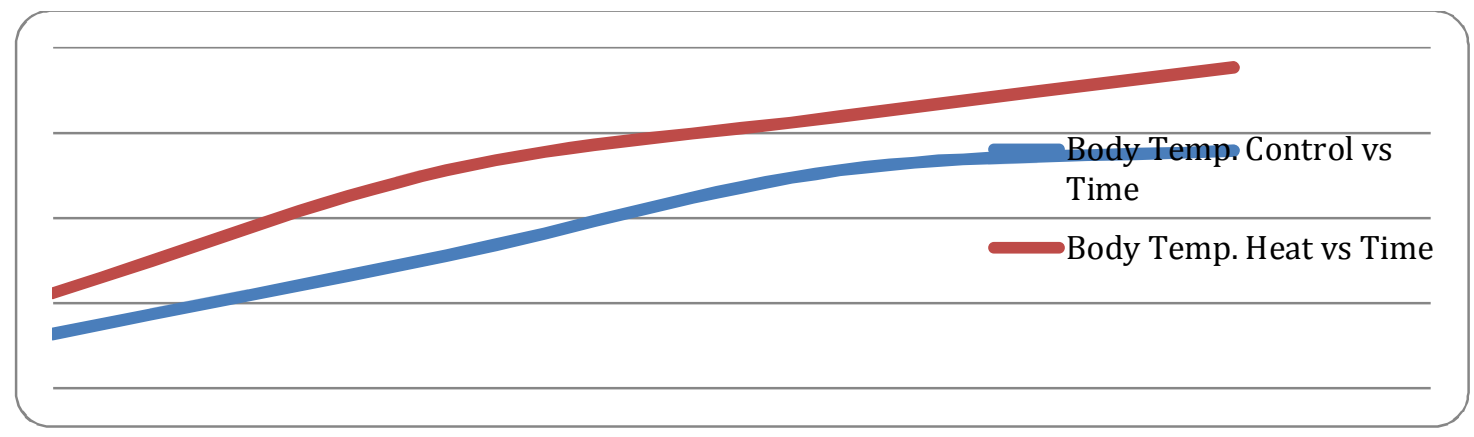

Figure 1. The average body temperature rate versus time during control and heat trials. 


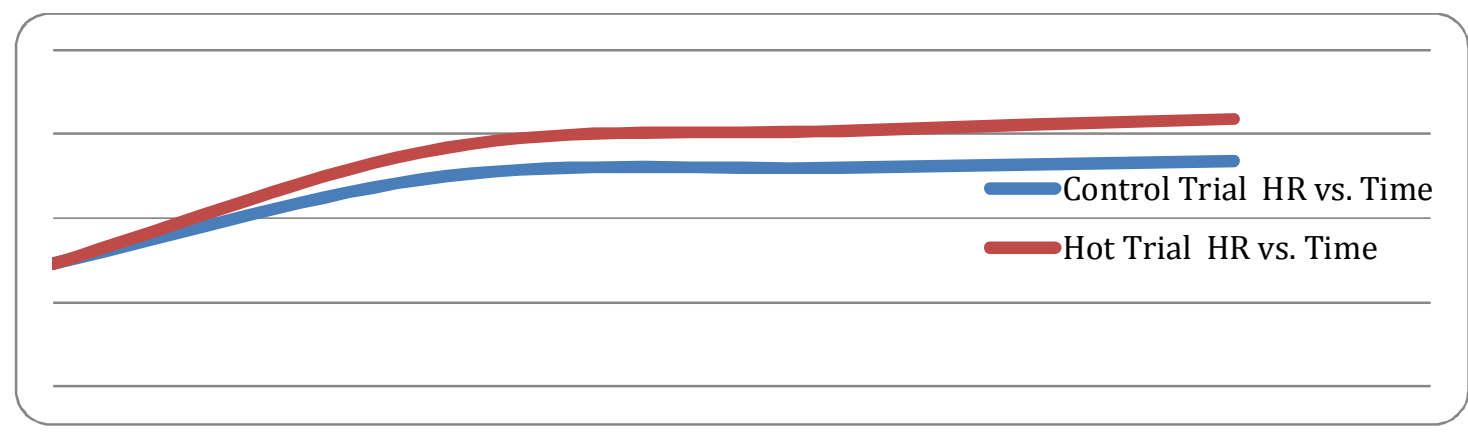

Figure 2. The average heart rate versus time during heat and control trials.

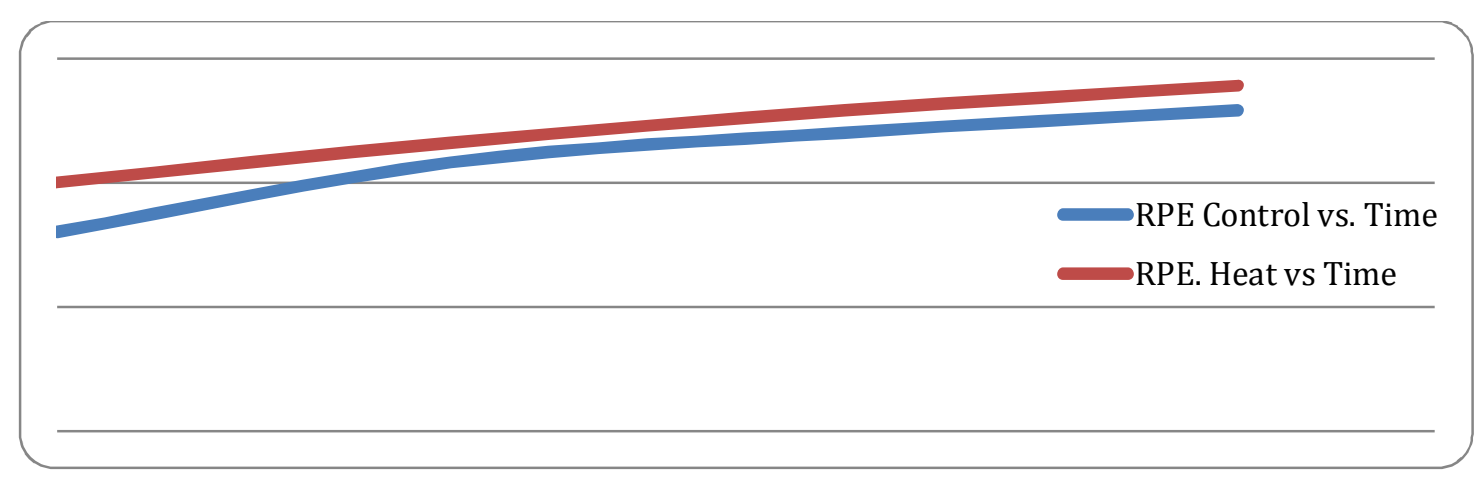

Figure 3. The average RPE vs. time during Control and heat trials for all subjects.

Table 2. Sweat rates during normal heat trials for each subject.

\begin{tabular}{ccccc}
\hline \multirow{2}{*}{ Subjects } & \multicolumn{2}{c}{ Control } & Heat & Sweat Rate $(\mathrm{L} / \mathrm{hr})$ \\
\cline { 2 - 5 } & Sweat Rate $(\mathrm{L} / \mathrm{hr})$ & $\begin{array}{c}\text { Sweat rate } \\
(\mathrm{L} / \mathrm{hr})\end{array}$ & $\begin{array}{c}\text { Sweat rate } \\
(\mathrm{L} / \mathrm{hr})\end{array}$ \\
\cline { 2 - 5 } & & & & \\
1 & $(110.66 \mathrm{~kg}-109.86 \mathrm{~kg}) / 0.5 \mathrm{hr}$ & 1.60 & $(110.66 \mathrm{~kg}-109.70 \mathrm{~kg}) / 0.5 \mathrm{hr}$ & 1.92 \\
2 & $(88.20 \mathrm{~kg}-87.76 \mathrm{~kg}) / 0.5 \mathrm{hr}$ & .89 & $(88.20 \mathrm{~kg}-86.85 \mathrm{~kg}) / 0.5 \mathrm{hr}$ & 2.70 \\
3 & $(63.39 \mathrm{~kg}-62.95 \mathrm{~kg}) / 0.5 \mathrm{hr}$ & .88 & $(63.95 \mathrm{~kg}-62.59 \mathrm{~kg}) / 0.5 \mathrm{hr}$ & .2 .72 \\
4 & $(121.09 \mathrm{~kg}-120.86 \mathrm{~kg}) / 0.5 \mathrm{hr}$ & .46 & $(121.77 \mathrm{~kg}-121.09 \mathrm{~kg}) / 0.5 \mathrm{hr}$ & 1.36 \\
5 & $(63.72 \mathrm{~kg}-63.58 \mathrm{~kg}) / 0.5 \mathrm{hr}$ & .28 & $(63.61 \mathrm{~kg}-63.31 \mathrm{~kg}) / 0.5 \mathrm{hr}$ & .60 \\
6 & $(83.79 \mathrm{~kg}-83.56 \mathrm{~kg}) / 0.5 \mathrm{hr}$ & .46 & $(83.56 \mathrm{~kg}-83.23 \mathrm{~kg}) / 0.5 \mathrm{hr}$ & .66 \\
7 & $(65.31 \mathrm{~kg}-65.08 \mathrm{~kg}) / 0.5 \mathrm{hr}$ & .46 & $(65.53 \mathrm{~kg}-64.97 \mathrm{~kg}) / 0.5 \mathrm{hr}$ & .1 .12 \\
8 & $(60.00 \mathrm{~kg}-59.70 \mathrm{~kg}) / 0.5 \mathrm{hr}$ & .60 & $(58.13 \mathrm{~kg}-57.60 \mathrm{~kg}) / 0.5 \mathrm{hr}$ & 1.06 \\
9 & $(85.81 \mathrm{~kg}-84.31 \mathrm{~kg}) / 0.5 \mathrm{hr}$ & .25 & $(84.81 \mathrm{~kg}-84.35 \mathrm{~kg}) / 0.5 \mathrm{hr}$ & .91 \\
10 & $(80.27 \mathrm{~kg}-79.67 \mathrm{~kg}) / 0.5 \mathrm{hr}$ & 1.20 & $(80.27 \mathrm{~kg}-79.07 \mathrm{~kg}) / 0.5 \mathrm{hr}$ & 2.40 \\
& & & & \\
\hline
\end{tabular}

Table 3. Drinking plan for each subject.

\begin{tabular}{|c|c|c|c|c|}
\hline \multirow{2}{*}{ Subject } & \multicolumn{2}{|c|}{ Control } & \multicolumn{2}{|c|}{ Heat } \\
\hline & Fluid to be replaced & Drinking plan & Fluid to be replaced & Drinking plan \\
\hline 1 & $1.60 \mathrm{~L} / \mathrm{hr} / 4=.40 \mathrm{~L} / \mathrm{hr}$ & $0.40 \mathrm{~L}$ every 15 minutes & $1.92 \mathrm{~L} / \mathrm{hr} / 4=.92 \mathrm{~L} / \mathrm{hr}$ & $0.48 \mathrm{~L}$ every 15 minutes \\
\hline 2 & $0.89 \mathrm{~L} / \mathrm{hr} / 4=0.22 \mathrm{~L} / \mathrm{hr}$ & $0.22 \mathrm{~L}$ every 15 minutes & $2.70 \mathrm{~L} / \mathrm{hr} / 4=0.7 \mathrm{~L} / \mathrm{hr}$ & $0.7 \mathrm{~L}$ every 15 minutes \\
\hline 3 & $0.88 \mathrm{~L} / \mathrm{hr} / 4=0.22 \mathrm{~L} / \mathrm{hr}$ & $0.22 \mathrm{~L}$ every 15 minutes & $2.72 \mathrm{~L} / \mathrm{hr} / 4=0.68 \mathrm{~L} / \mathrm{hr}$ & $0.68 \mathrm{~L}$ every 15 minutes \\
\hline 4 & $0.46 \mathrm{~L} / \mathrm{hr} / 4=0.12 \mathrm{~L} / \mathrm{hr}$ & $0.12 \mathrm{~L}$ every 15 minutes & $1.36 \mathrm{~L} / \mathrm{hr} / 4=0.34 \mathrm{~L} / \mathrm{hr}$ & 0.34 L every 15 minutes \\
\hline 5 & $0.28 \mathrm{~L} / \mathrm{hr} / 4=0.07 \mathrm{~L} / \mathrm{hr}$ & $0.07 \mathrm{~L}$ every 15 minutes & $0.6 \mathrm{~L} / \mathrm{hr} / 4=0.15 \mathrm{~L} / \mathrm{hr}$ & $0.15 \mathrm{~L}$ every 15 minutes \\
\hline 6 & $0.46 \mathrm{~L} / \mathrm{hr} / 4=0.12 \mathrm{~L} / \mathrm{hr}$ & $0.12 \mathrm{~L}$ every 15 minutes & $0.66 \mathrm{~L} / \mathrm{hr} / 4=0.17 \mathrm{~L} / \mathrm{hr}$ & 0.17 L every 15 minutes \\
\hline 7 & $0.46 \mathrm{~L} / \mathrm{hr} / 4=0.12 \mathrm{~L} / \mathrm{hr}$ & $0.12 \mathrm{~L}$ every 15 minutes & $1.12 \mathrm{~L} / \mathrm{hr} / 4=0.28 \mathrm{~L} / \mathrm{hr}$ & $0.28 \mathrm{~L}$ every 15 minutes \\
\hline 8 & $0.6 \mathrm{~L} / \mathrm{hr} / 4=0.15 \mathrm{~L} / \mathrm{hr}$ & $0.15 \mathrm{~L}$ every 15 minutes & $1.06 \mathrm{~L} / \mathrm{hr} / 4=0.27 \mathrm{~L} / \mathrm{hr}$ & $0.27 \mathrm{~L}$ every 15 minutes \\
\hline 9 & $0.25 \mathrm{~L} / \mathrm{hr} / 4=0.23 \mathrm{~L} / \mathrm{hr}$ & $0.06 \mathrm{~L}$ every 15 minutes & $0.91 \mathrm{~L} / \mathrm{hr} / 4=0.23 \mathrm{~L} / \mathrm{hr}$ & $0.23 \mathrm{~L}$ every 15 minutes \\
\hline 10 & $1.20 \mathrm{~L} / \mathrm{hr} / 4=0.6 \mathrm{~L} / \mathrm{hr}$ & $0.3 \mathrm{~L}$ every 15 minutes & $2.40 \mathrm{~L} / \mathrm{hr} / 4=0.6 \mathrm{~L} / \mathrm{hr}$ & $0.6 \mathrm{~L}$ every 15 minutes \\
\hline
\end{tabular}

Turk J Sport Exe 2014; I6(I): 135-139 


\section{DISCUSSION}

Many studies indicated that body weight loss during moderate exercise in the heat results in progressive increases in core and muscle temperature $(9,10,11,12,17)$. For example, during two hours of cycling in the heat $\left(65 \% \mathrm{VO} 2 \mathrm{max} ; 35^{\circ} \mathrm{C} ; 95^{\circ} \mathrm{F}\right)$, core temperature, and perceived exertion ratings significantly increased over time compared to normal conditions, while blood volume, stroke volume, cardiac output, and skin blood flow decreased (17). Similar results were reported by Mountain and Coyle (17) who demonstrated that levels of dehydration of $1 \%, 2 \%, 3 \%$, and $4 \%$ of body mass were increasingly detrimental to cardiovascular and thermoregulatory function (19). Increased body temperature increases blood flow to the skin affects the volume of blood pooled in the cutaneous vessels such that more blood is diverted to the cutaneous blood vessels. When extra blood is accumulated in cutaneous blood vessels, there will be less blood flow back to the heart; so, it will decrease the venous return and diastolic filing in the heart. Since end-diastolic volume is decreased, there will be less stretching and contraction in the cardiac muscle and it will decrease the amount of blood ejected from the heart; thus, stroke volume will be decreased and heart rate will be increased to maintain cardiac output. To maintain the same cardiac output during normal and hot environments and HR values must increase more in hot environment; it means that stroke volume is decreased in the hot environment and HR was increased in order to maintain the same cardiac output and blood demand for the muscles (1). A continuous increase in heart rate after the onset of exercise in the warm and normal conditions occurred because of increased metabolism and exercise exertion. Our data indicates that HR (Figure 1) and RPE (Figure 3) increase more in hot environment and it is consistent with the current literature.

According to our data, body temperature increased as expected during exercise in both normal and warm conditions. The difference in body temperature between the two conditions was significantly higher when exercising during the wearing multiple layers of clothing. Increased ambient temp and layers of clothing caused increase body temp in the hot trial in this study. To explain this: one mechanism that helps the body to dissipate heat is the vasodilation of cutaneous blood vessels.
This allows heat produced to be transported to the skin surface where part of the heat can be radiated/ evaporated to the environment. The body temperature for the control trial gradually increases because metabolic heat is being produced by skeletal muscle due to exercise. However, body temperature for the heat trial increases linearly and does not plateau. Due to the fact the subjects are wearing many layers of clothing and increased ambient temperature, the body temperature increases. This is because the gradient for dry heat exchange compromises evaporative heat exchange. The body cannot maintain steady state core temperature without evaporation that can cause cardiovascular strain due to an increase in high skin blood flow and dehydration $(13,14,15,16,23,24,25,26)$.

RPE data also supports that hot environment is more stressful than normal environment since the muscles fell more exertion in hot environment than normal environment and heart rate has to increase to maintain cardiac output and balance the blood pressure. The greater the stress imposed by the exercise training stimulus, the greater the challenge to overall homeostasis each time the stimulus is applied. Adaptations are intended to reduce the acute challenge to homeostasis. During exercise in heat, primary cardiovascular challenge is to increase cardiac output sufficiently to support both high skin blood flows for heat dissipation and high muscle blood flow for metabolism (1).

Dehydration's influence on physiological function is superior in warm environments than in cold (1). Dehydration's effect on a variety of cardiovascular and thermoregulatory functions is noticeable early in exercise (e.g., within $30 \mathrm{~min}$ ) at a body mass loss of about 1\% (15). Cheuvront et al. (1, 15) point out that for many physically active people, drinking around $1 \mathrm{~L} / \mathrm{h} \backslash$ will typically supply adequate water, carbohydrate, and electrolytes to limit dehydration to less than $2 \%$ body mass and provide an additional performance benefit (1). However, lower levels of dehydration can also damage performance even during comparatively short-duration, intermittent exercise. In our study, weight loss during normal condition $(0.57 \%)$ and heat trial $(1.05 \%)$ might have detrimental effect on athletes' performance. Though, not many studies and guidance were presented on low-level of dehydration (less than $1 \%$ ); therefore, this study determined the sweat rates 
and fluid needs for different weight categories for physically active colligate students who lost $1 \%$ of their total weight during 30 minutes of cycling exercise during both normal and warm conditions (Table 2, and 3). We think this will help physically active college aged youngsters guide them to better hydrate than dehydrated.

To sum up, the amount of fluid needed during physical activity is dependent on the sweat rates, exercise intensity and duration, and body temperature, fluid intake is possibly the simplest and most efficient means of supporting physiological function and improving physical performance.

\section{REFERENCES}

1. American College of Sports Medicine. Guidelines for Exercise Testing and Prescription. Lippincott Williams and Wilkins, Baltimore, 2000.

2. Bynum GD, Pandolf KB, Schuette WH, Goldman RF, Lees DE, Whang-Peng J, Atkinson ER, Bull JM. Induced hyperthermia in sedated humans and the concept of critical thermal maximum. Am J Physiol Regul Integr Comp Physiol, 1978; 235: R228-R236.

3. Dessai S. Heat stress and mortality in Lisbon Part I. model construction. Int J Biometeorol, 2002; 47: 6-12.

4. Environmental Physiology, ed. Fregly MJ \& Blatteis CM, chapt 11, pp. 215-243. Oxford University Press, New York, 1996.

5. Ekelund LG. Circulatory and respiratory adaptation during prolonged exercise. Acta Physiol Scand, 1967; 70 (Suppl. 68), 538.

6. Galloway SD. Dehydration, rehydration, and exercise in the heat: Rehydration strategies for athletic competition. Can J Appl Physiol, 1999; 24(2): 188-200.

7. Grosman B, Shaik OS, Helwig BG, Leon LR, Doyle III FJ. A physiological systems approach to modeling and resetting of mouse thermoregulation under heat stress. J Appl Physiol, 2011; 111: 938-945.

8. González-Alonso J, Teller C, Andersen SL, Jensen FB, Hyldig T, Nielsen B. Influence of body temperature on the development of fatigue during prolonged exercise in the heat. J Appl Physiol, 1999; 86: 1032-1039.

9. Gonz'alez-Alonso J. Hyperthermia impairs brain, heart and muscle function in exercising humans. Sports Med, 2007; 37: 371-373.
10. Gonz'alez-Alonso J, Calbet JA. Reductions in systemic and skeletal muscle blood flow and oxygen delivery limit maximal aerobic capacity in humans. Circulation, 2003; 107: 824-830.

11. Hargreaves M, Dillo P, Angus D, Howlett K, Conus NM, Febbraio M. Effect of fluid ingestion on muscle metabolism during prolonged exercise. J Appl Physiol, 1996; 81: 1594-1597.

12. Johnson JM. Exercise and the cutaneous circulation. Exerc Sports Sci Rev, 1992; 20: 59-97.

13. Johnson JM, Proppe DW. Cardiovascular adjustments to heat stress. In Handbook of Physiology, section 4, 1996.

14. Johnson JM, Rowell LB. Forearm skin and muscle vascular responses to prolonged leg exercise in man. J Appl Physiol, 1975; 39: 920-924.

15. Kenefick RW, Cheuvront SN. Hydration for recreational sport and physical activity. Nutr Rev, 2012; 70 (Suppl. 2): S137-142.

16. Montain SJ, Coyle EF. Influences of grade dehydration on hyperthermia and cardiovascular drift during exercise. J Appl Physiol, 1992; 73: 1340-1350.

17. Murray B. Hydration and physical performance. Journal of the American College of Nutrition, 2007; 26(5): 542S-548S.

18. Nybo L. Brain temperature and exercise performance. Exp Physiol, 2012; (3): 333-339.

19. Keller DM, Cui J, Davis SL, Low DA, Crandall CG. Heat stress enhances arterial baroreflex control of muscle sympathetic nerve activity via increased sensitivity of burst gating, not burst area, in humans. J Physiol 2006; 573: 445-451.

20. Kellogg DL Jr, Johnson JM, Kenny WL, P'ergola PE, Kosiba WA. Mechanisms of control of skin blood flow during prolonged exercise in humans. Am J Physiol Heart Circ Physiol, 1993; 265: H562-H568.

21. Kellogg DL Jr, Johnson JM, Kosiba WA. Elevation of the internal temperature threshold for active cutaneous vasodilation by dynamic exercise. J Appl Physiol, 1991; 71: 2476-2482.

22. Kellogg DL Jr, P'ergola PE, Kosiba WA, Grossmann M, Johnson JM. Cutaneous active vasodilation in humans is mediated by cholinergic nerve co-transmission. Circ Res, 1995; 77: 1222-1228.

23. Maughan RJ, Shirre M. Dehydration and rehydration in competitive sport. Scand J Med SciSports, 2010; (Suppl 3): 40-47.

24. Smolander J, Saalo J, Korhonen O. Effect of workload on cutaneous vascular response to exercise. J Appl Physiol, 1991; 71: 1614-1619. 